\title{
Triage of febrile children at a GP cooperative: determinants of a consultation
}

\author{
Miriam Monteny, Marjolein Y Berger, Johannes C van der Wouden, Berth J Broekman and Bart W Koes
}

\section{ABSTRACT}

\section{Background}

Most febrile children contacting a GP cooperative are seen by a GP, although the incidence of serious illness is low. The guidelines for triage might not be suitable in primary care.

Aim

To investigate the determinants related to the outcome of triage in febrile children.

Design of study

Cross-sectional study.

Setting

Dutch GP cooperative.

Method

Receptionists filled out a triage questionnaire when parents called regarding their febrile child (aged between 3 months and 6 years) and estimated the level of concern of the parents. The outcome was either telephone advice, a consultation, or a home visit. Children were divided in subgroups based on age $<18$ months or $\geq 18$ months, and prognostic models for a consultation were constructed.

\section{Results}

Of 422 children, $73 \%$ were seen by a GP. Children aged $<18$ months were more likely to be seen when their parents reported less drinking or shortness of breath. In children aged $\geq 18$ months, a duration of fever of $\geq 3$ days, drowsiness, or a pale, ashen, or mottled skin were predictors of consultation. Children with alarm symptoms were seen according to the guideline. In both subgroups, children without alarm symptoms were more likely to be seen when their parents were concerned.

\section{Conclusion}

The available guideline was followed to a large extent at a GP cooperative. Because, surprisingly, most children were reported to have alarm symptoms, the validity of the triage questions asking parents about alarm symptoms is questionable.

\section{Keywords}

after-hours care; child; fever; infant; practice guideline; preschool; triage.

\section{INTRODUCTION}

Fever in children is a frequent reason for parents to contact a GP, 1 and is often presented in the evening, during out-of-office hours. During these hours, GP care in the Netherlands is currently mainly provided by GP cooperatives. ${ }^{2}$ Initial contact of patients with the GP cooperative is by telephone, with trained receptionists. Triage is based on the practice guideline for the management of febrile children by the Dutch College of General Practitioners (NHG). ${ }^{3,4}$

According to available guidelines, triage of a febrile child is based (among other characteristics) on the child's age, characteristics of the fever, the presence of alarm symptoms, and concern of the parents. ${ }^{3,5}$ In the absence of alarm symptoms and in agreement with the parents, advice by telephone is considered to be adequate care in children older than 3 months.

Most febrile children have self-limiting viral infections and do not need medical intervention. The incidence of serious bacterial infections, such as pneumonia, sepsis, meningitis, and bacterial gastroenteritis, is very low in general practice., Nevertheless, most of the children contacting primary care are seen by the GP, thereby creating a high workload.

M Monteny, MD, GP trainee and PhD student; MY Berger, $M D, P h D, G P$ and associate professor; JC van der Wouden, $P h D$, associate professor; BW Koes, $P h D$, professor of general practice, Department of General Practice, Erasmus MC; BJ Broekman, RN, manager GP Cooperative South, Groene Hilledijk, Rotterdam, The Netherlands.

Address for correspondence

Dr Marjolein Y Berger, Erasmus MC, Department of General Practice, Room Ff 322, PO Box 2040, 3000 CA Rotterdam, The Netherlands.

E-mail: m.berger@erasmusmc.nl

Submitted: 24 July 2007; Editor's response: 19 September 2007; final acceptance: 19 December 2007.

(C)British Journal of General Practice.

This article was originally online first. Cite this article as: Br J Gen Pract 2008; 58: 242-247. Advance online publication. DOI: $10.3399 /$ bjgp08X279643 
The reason for this discrepancy might be that the available guidelines for triage are not suitable for primary care. First, most of the evidence in the guidelines comes from studies in selected and referred children. Furthermore, the evidence is derived from studies performed in the era before the present childhood vaccination schedules, with a different spectrum of bacterial infections and thus incidence and presentation. Thirdly, in the Netherlands, GPs are no longer familiar with the patients they see at the GP cooperative, due to the change in organisation of out-of-hours primary care. Therefore, a thorough evaluation of the present triage process and its determinants seems appropriate in order to optimise triage of febrile children in primary care.

The aim of this study is to investigate the triage process of febrile children presenting to a GP cooperative. The objective was to describe the determinants related to the outcome of triage: telephone advice, consultation at the GP cooperative, or home visit.

\section{METHOD}

This study was conducted as part of a prospective cohort study evaluating the course of fever in children aged 3 months to 6 years, performed at a large GP cooperative in the southern part of Rotterdam, a large multicultural city in the Netherlands. The GP cooperative comprises an area of 300000 inhabitants. Between January 2005 and March 2006, consecutive children aged 3 months to 6 years contacting the GP cooperative with fever, as reported by their parents, during Monday to Thursday evenings, were eligible for inclusion. Fever had to be the main reason for encounter. Children were excluded in cases where the parents could not communicate in Dutch, and in cases where a child had already been included within the last 2 weeks.

When parents telephoned concerning their febrile child, the receptionists of the GP cooperative performed their usual triage. After making their triage decision they filled out a structured triage questionnaire concerning eight items with a total of 26 questions. The receptionist was not aware of the research question. The questionnaire consisted of triage questions derived from the $\mathrm{NHG}$ practice guideline. ${ }^{3}$ The answer categories were 'yes', 'no', or 'unclear or not applicable'. Duration of fever $\geq 3$ days, shortness of breath, signs of dehydration, meningism, or serious illness are alarm symptoms indicating an increased risk for complications.

At the end of the telephone call, the receptionists were asked to assess the level of concern of the parent(s), categorised as: not concerned, slightly concerned, moderately concerned, or seriously

\section{How this fits in}

Febrile children presenting to primary care usually have a self-limiting infection without a need for medical intervention. Nevertheless, many febrile children are seen by a GP during out-of-hours care. This study shows that as much as $73 \%$ of children presented at a GP cooperative in the Netherlands are seen by a GP. Most of these children were reported to have alarm symptoms, leading to the conclusion that the triage guideline is well used by receptionists, but the telephonic enquiry after alarm symptoms needs refinement.

concerned. The outcome parameter of this study was the result of the triage: telephone advice only, a consultation at the GP cooperative, or a home visit.

\section{Statistical analysis}

The characteristics of children with the triage result 'advice' were compared to the characteristics of the children with the triage result 'consultation' and 'home visit', using univariate logistic regression analysis. The children were divided into subgroups based on age. Three of the triage questions, addressing throat ache, stomach ache, and crying during nappy change, were not applicable to all children. The age distributions of the children whose parents answered 'yes' or 'no' to the questions on sore throat and stomach ache were compared with those of the children whose parents could not answer these questions. Based on this, the age of 18 months was chosen as the cut-off point. Since most children aged $<18$ months wear nappies, this cut-off point was also used for the triage question regarding crying during nappy change. The differences between the baseline characteristics of the two age groups were compared by means of a $\chi^{2}$ test.

Based on the defined age groups, two prognostic models for consultation as outcome of triage were constructed using multiple logistic regression analysis, in which the clinically important variables age, sex, and duration of fever were entered first. Secondly, all other triage questions were added using a stepwise backward approach. At each step, the least-significant variable was removed, using a significance level of 0.05 (Wald test). Age and body temperature were analysed as continuous variables. The expected probability of consultation for each child was calculated using the regression coefficients of the independent variables found to be present in the child. The discriminative ability of the model was assessed using the area under the Receiver Operating Characteristic (ROC) curve (AUC). An AUC of 1 indicates perfect discrimination between children with a consultation and those with advice only; an AUC of 0.5 indicates no discrimination at all. 


\begin{tabular}{|c|c|c|}
\hline Characteristic & $\begin{array}{c}<18 \text { months } \\
n=184, n(\%)\end{array}$ & $\begin{array}{c}\geq 18 \text { months } \\
n=238, n(\%)\end{array}$ \\
\hline Males & $110(59.8)$ & $132(55.5)$ \\
\hline$\geq 3$ days' fever & $45(24.5)$ & $68(28.6)$ \\
\hline Consultation & $137(74.5)$ & $172(72.3)$ \\
\hline Non-native & $99(53.8)$ & $122(51.3)$ \\
\hline Median age in months (range) & $9.7(3-17.8)$ & $36.0(18-71)$ \\
\hline Mean temperature in ${ }^{\circ} \mathrm{C}$ : (standard error) & $39.4(0.06)$ & $39.5(0.05)$ \\
\hline
\end{tabular}

The cultural background (native versus non-native) and level of concern of the parents (not or slightly concerned versus moderately or seriously concerned) were separately added to the final model in each subgroup, testing for additional value in the prognostic regression model, using a significance level of 0.05 (Wald test).

The SPSS statistical package (version 11.01) was used for data entry and analysis.

\section{RESULTS}

Of the 506 children enrolled in the prospective study, the triage questionnaire was filled out in 422 $(83.4 \%)$ cases. The 422 children with a triage questionnaire did not differ from the 84 children without triage questionnaire regarding age, sex, residence, triage result, percentage non-native, and percentage referred by the GP to secondary care. Triage of the 422 children resulted in a consultation at the GP cooperative in 309 (73\%) children (consultation group) and telephone advice

\begin{tabular}{|c|c|c|c|c|c|c|}
\hline & \multicolumn{3}{|c|}{$<18$ months $(n=184)$} & \multicolumn{3}{|c|}{$\geq 18$ months $(n=238)$} \\
\hline & $\begin{array}{c}\text { Consultation } \\
n=137, n(\%\end{array}$ & $\%) \quad$ OR (95\% Cl) & $P$-value & $\begin{array}{c}\text { Consultation } \\
n=172, n(\%)\end{array}$ & o) OR $(95 \% \mathrm{Cl})$ & $P$-value \\
\hline \multicolumn{7}{|l|}{ General } \\
\hline Median age in months & 9.4 & 0.99 (0.91 to 1.07$)$ & 0.800 & 35.7 & 0.99 (0.97 to 1.01$)$ & 0.250 \\
\hline Male sex & $87(63.5)$ & $1.82(0.93$ to 3.55$)$ & 0.081 & $103(59.9) 1$ & 1.91 (1.07 to 3.38$)$ & 0.028 \\
\hline \multicolumn{7}{|l|}{ Fever } \\
\hline Mean temperature $\left({ }^{\circ} \mathrm{C}\right)$ & 39.4 & 0.92 (0.58 to 1.46$)$ & 0.730 & 39.5 & 0.89 (0.61 to 1.30$)$ & 0.540 \\
\hline Duration $\geq 3$ days & $40(29.2)$ & 3.28 (1.21 to 8.94$)$ & 0.020 & $60(34.9) 3$ & 3.92 (1.76 to 8.77$)$ & 0.001 \\
\hline Fever earlier in week & $29(21.2)$ & 1.85 (0.72 to 4.79$)$ & 0.20 & $40(23.3)$ & 1.78 (0.83 to 3.81$)$ & 0.140 \\
\hline \multicolumn{7}{|l|}{ Respiratory tract } \\
\hline Cough & $99(72.3)$ & 2.34 (1.17 to 4.70$)$ & 0.017 & $108(62.8)$ & $0.86(0.47$ to 1.57$)$ & 0.630 \\
\hline Running/blocked nose & $103(75.2)$ & $2.12(1.05$ to 4.27$)$ & 0.036 & $104(60.5)$ & 0.91 (0.51 to 1.65$)$ & 0.770 \\
\hline Shortness of breath & $79(57.7)$ & 3.18 (1.55 to 6.53$)$ & 0.002 & $85(49.4) 2$ & 2.62 (1.42 to 4.82$)$ & 0.002 \\
\hline Earache/pulling at ear(s) & $47(34.3)$ & 2.56 (1.09 to 6.00$)$ & 0.030 & $56(32.6)$ & $2.13(1.07$ to 4.25$)$ & 0.032 \\
\hline Sore throat & - & - & - & $54(31.4)$ & 1.26 (0.66 to 2.41$)$ & 0.480 \\
\hline \multicolumn{7}{|l|}{ Gastrointestinal tract } \\
\hline Vomiting & $62(45.3)$ & $4.79(2.00$ to 11.4$)$ & 0.000 & $62(36.0) 2$ & 2.32 (1.17 to 4.59$)$ & 0.016 \\
\hline Diarrhoea & $40(29.2)$ & 2.02 (0.87 to 4.72$)$ & 0.100 & $42(24.4)$ & $1.82(0.86$ to 3.89$)$ & 0.120 \\
\hline Stomach ache & - & - & - & $71(41.3)$ & $1.76(0.94$ to 3.27$)$ & 0.075 \\
\hline \multicolumn{7}{|l|}{ Dehydration } \\
\hline Drinking less than normal & $72(52.6)$ & 4.65 (2.08 to 10.4$)$ & 0.000 & $96(55.8) 2$ & 2.87 (1.55 to 5.29$)$ & 0.001 \\
\hline Less urine voiding & $42(30.7)$ & 1.95 (0.86 to 4.43$)$ & 0.110 & $59(34.3)$ & 1.95 (0.94 to 4.02$)$ & 0.072 \\
\hline \multicolumn{7}{|l|}{ Meningism } \\
\hline Crying during nappy change & $66(48.2)$ & 2.25 (1.10 to 4.61$)$ & 0.027 & - & - & - \\
\hline Crying when lifting up & $36(26.3)$ & 2.07 (0.85 to 5.04$)$ & 0.110 & $57(33.1) 2$ & 2.32 (1.12 to 4.82$)$ & 0.024 \\
\hline \multicolumn{7}{|l|}{ Seriously ill } \\
\hline Drowsiness & $61(44.5)$ & 3.44 (1.54 to 7.68$)$ & 0.003 & $101(58.7)$ & 4.39 (2.32 to 8.27$)$ & $<0.001$ \\
\hline Crying inconsolably & $25(18.2)$ & 1.96 (0.71 to 5.47$)$ & 0.200 & $37(21.5)$ & 1.72 (0.78 to 3.81$)$ & 0.180 \\
\hline Restlessness & $80(58.4)$ & 2.53 (1.26 to 5.08$)$ & 0.009 & $82(47.7)$ & 1.47 (0.82 to 2.62$)$ & 0.200 \\
\hline Groaning & $73(53.3)$ & 3.65 (1.73 to 7.70$)$ & 0.001 & $70(40.7) 2$ & $2.10(1.12$ to 3.96$)$ & 0.022 \\
\hline Pale, ashen, or mottled skin & $54(39.4)$ & 2.76 (1.22 to 6.22$)$ & 0.015 & $83(48.3)$ & 3.94 (1.99 to 7.79$)$ & $<0.001$ \\
\hline Skin rash & $21(15.3)$ & 1.47 (0.52 to 4.17$)$ & 0.470 & $28(16.3)$ & 4.16 (1.22 to 14.2$)$ & 0.023 \\
\hline \multicolumn{7}{|l|}{ Other } \\
\hline Other symptoms noticed & $70(51.1)$ & 1.77 (0.89 to 3.54$)$ & 0.100 & $74(43.0)$ & 1.33 (0.73 to 2.43$)$ & 0.350 \\
\hline Differently ill & $89(65.0)$ & 2.78 (1.31 to 5.91$)$ & 0.008 & $110(64.0)$ & 4.00 (2.16 to 7.40$)$ & $<0.001$ \\
\hline Comorbidity & $14(10.2)$ & $>100$ & 0.000 & $21(12.2)$ & 2.21 ( 0.73 to 6.72$)$ & 0.160 \\
\hline
\end{tabular}

${ }^{\circ} \mathrm{C}=$ degrees celsius. $\mathrm{OR}=$ odds ratio. 
in $113(27 \%)$ children (advice group); no children were visited at home. The median age was 21 months (range 3-71 months). The number of male children was 242 (57\%), and 214 children (51\%) had non-native parents. There were 184 children aged $<18$ months and 283 were aged $\geq 18$ months. The main characteristics of both age groups are listed in Table 1. The most common symptoms at triage were a running or blocked nose and cough (63-75\%). Furthermore, the symptoms indicative of meningism and serious illness were frequently reported; crying during nappy change was reported in $48 \%$ of children aged $<18$ months. Drowsiness, restlessness, groaning, and a pale, ashen, or mottled skin was reported by the parents of about $40 \%$ to more than $50 \%$ of children. The frequencies of the triage answers, the alarm symptoms, and their univariate association with consultation and their univariate association with consultation as the outcome of triage, as odds ratios with 95\% confidence intervals are listed in Table 2. In children aged $<18$ months, 14 of the 24 variables were significantly associated with consultation $(P=0.05)$, compared to 12 of 25 in children aged $\geq 18$ months.

The prognostic model for both age groups is presented in Table 3. Children aged $<18$ months
Table 3. Alarm symptoms predicting consultation as triage result in children aged $<18$ months and children aged $\geq 18$ months in a multivariable logistic regression model.

\begin{tabular}{lcc} 
Age group & OR $(95 \% \mathrm{Cl})$ & $P$-value \\
\hline $\begin{array}{l}\text { Children }<18 \text { months } \\
\quad \text { Drinking less than normal }\end{array}$ & $4.51(1.95$ to 10.4$)$ & $<0.001$ \\
$\quad$ Shortness of breath & $3.00(1.40$ to 6.42$)$ & 0.005 \\
\hline Children $\geq 18$ months & & \\
$\quad$ Duration of fever $\geq 3$ days & $3.70(1.49$ to 9.22$)$ & 0.005 \\
$\quad$ Drowsiness & $4.64(2.29$ to 9.38$)$ & 0.000 \\
Pale, ashen, or mottled skin & $3.75(1.74$ to 8.07$)$ & 0.001 \\
\hline
\end{tabular}

whose parents reported that their child was drinking less than normal or was short of breath, were more likely to be invited for consultation. In children aged $\geq 18$ months a duration of fever of $\geq 3$ days, drowsiness, or a pale, ashen or mottled skin, was predictive for a consultation. The $c$ value of the AUC was 0.73 for children aged $<18$ months, and 0.79 for children aged $\geq 18$ months, indicating a good discriminative ability for consultation of both models.

In both age groups, the rate of consultation was not significantly different between children whose parents were non-native or native. However, the rate of consultations was higher in children whose parents were concerned according to the

Table 4. Predictive value of triage questions on consultation as triage result, and the additional value of concerned parents of febrile children.

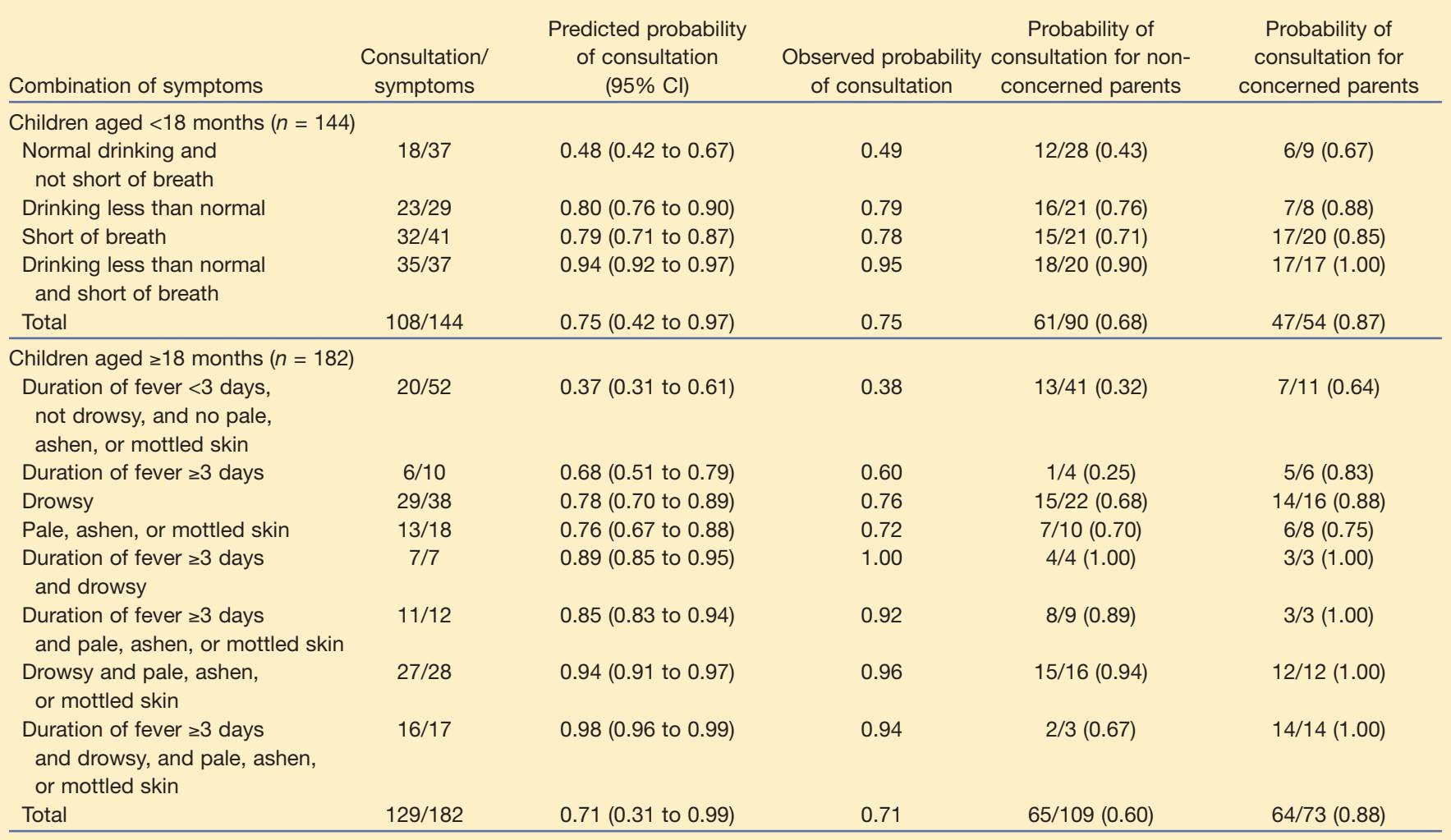


receptionist, compared to the children whose parents were not concerned. Table 4 presents the observed and expected probability of a consultation in children with each predictive symptom or combination of symptoms, followed by the probability of a consultation in children with and in children without concerned parents. Children aged $<18$ months who did not drink less and were not short of breath were least likely to be seen by the GP (12 out of 28), but the probability of a consultation increased when their parents were concerned (six out of nine). When children had at least one of these symptoms, the additional value of concern of parents to the probability of a consultation was very small. Children aged $\geq 18$ months who were not drowsy and did not have a pale, ashen, or mottled skin, and had a duration of fever $<3$ days, were least likely to be seen by the GP (13 out of 41 ), but the likelihood increased when their parents were concerned (7/11). This was also the case when children had a duration of fever $\geq 3$ days, but were not drowsy and had no pale, ashen, or mottled skin. The additional value of parental concern for the probability of a consultation was negligible when children had a combination of these symptoms.

Children with two or more of the alarm symptoms, were more likely to be referred to a pediatrician than those without alarm symptoms (0\% versus $14 \%$ in children aged $<18$ months and $2 \%$ versus $12 \%$ in children aged $\geq 18$ months).

The discriminative ability ( $\chi^{2}$ value) of the model in children aged $<18$ months increased from 0.73 to 0.77 , and in children aged $\geq 18$ months from 0.79 to 0.83 when concern of parents was added.

\section{DISCUSSION}

\section{Summary of main findings}

Of 422 children whose parents contacted the out-ofhours GP cooperative for fever, $73 \%$ subsequently consulted the GP and $27 \%$ received advice by telephone only. Independent characteristics predicting a consultation were different for children aged $<18$ months and those aged $\geq 18$ months. Children aged $<18$ months whose parents reported less drinking or shortness of breath, were more likely to be seen by the GP, whereas in children aged $\geq 18$ months, a duration of fever $\geq 3$ days, drowsiness, and a pale, ashen, or mottled skin were independent predictors of consultation. Children without alarm symptoms were more likely to be seen when the parents were moderately or seriously concerned.

\section{Strengths and limitations of the study}

To the authors' knowledge, this is the first study describing the triage process in febrile children in an out-of-hours primary care setting. The receptionists were instructed to perform their usual triage and then check the questionnaire for questions not asked, and to fill out the complete questionnaire. This might have biased the consultation rate if certain questions had not yet been asked and made the receptionist change the triage result from advice to a consultation. However, the symptoms that were found most predictive of a consultation are important alarm symptoms according to the ruling triage guideline. It is likely that these questions already played a role in the outcome, before the triage questionnaire was checked. Furthermore, a pilot study was conducted before the start of this study, in which the consultation rate was $66 \%$, which is similar to the rate in the present study (73\%).

This study's outcome measure was whether a child was advised to attend for a consultation or not. This outcome is in fact an index of how likely a call handler thinks a child is to have a severe disease. This will be influenced by the consensus of which indicators carry most weight; these indicators are described in prevailing guidelines. To evaluate whether triage outcome reflects severity of disease, the probability of consultation was related to the probability of referral to a paediatrician: an index of severity of disease that is probably more reliable. Because of the small numbers of referred children, these results should be interpreted with caution.

Comorbidity in children was univariately strongly associated with consultation in children aged $<18$ months, but not in children aged $\geq 18$ months, and was not included in the final model. This may be due to the relatively small number of children with reported comorbidity in the study sample. It is likely that comorbidity (such as asthma or congenital disorders) plays a significant role in triage, since almost all children with comorbidity in our study were seen by a GP.

\section{Comparison with existing literature}

To the authors' knowledge, this study is the first to describe the determinants of the outcome of triage in febrile children during GP out-of-hours care. A recently published guideline for feverish illness in children $<5$ years old reported alarm symptoms for intermediate or high risk of serious illness, ${ }^{5}$ which are comparable to the alarm symptoms of the $\mathrm{NHG}$ guideline used in this study.

\section{Implications for future research and clinical practice}

The consultation rate of $73 \%$ is high. A lower rate would be expected, since most febrile children have self-limiting infections and do not need medical intervention. In total, $83 \%$ of children aged 
$<18$ months and $85 \%$ of children aged $\geq 18$ months in the models, who were seen by the GP, were reported to have at least one of the alarm symptoms drinking less than normal, shortness of breath, drowsiness, pale, ashen, or mottled skin, and a duration of fever $\geq 3$ days (Table 4). According to these results, the receptionists followed the available guidelines to a large extent.

In addition it was found that the alarm symptoms asked for by the receptionist to some extent reflect the seriousness of illness. Children with two or more of the alarm symptoms selected in the multivariate model had a higher probability of referral than those without. In contrast, it is doubtful whether parents entirely understood the questions, as it is not likely that so many children had alarm symptoms. To improve cost-effectiveness of triage, the validity of the inquiry relating to alarm symptoms should therefore be questioned and needs further research.

Surprisingly, in children aged $<18$ months drowsiness fell out of the model. In this age group children who did not drink well were almost always reported to be drowsy, and vice versa: if they drank well the children were hardly reported as drowsy. This indicates that in these small children drowsiness might be evaluated by the parents on the ability of their child to drink properly. In the analyses carried out in this study this indicates that there is no additional value in asking about drowsiness in cases where the child does not drink well.

Parental concern is a good reason for consultation. In this study, children without alarm symptoms were more likely to be seen by a GP when their parents were concerned. However, when alarm symptoms were present, the concern of parents hardly increased the probability of a consultation; these children were already very likely to be seen. It might be useful to further explore the value of parental concern in the discrimination of febrile children in need of a medical intervention from those who are not in need.

\section{Funding body}

This study was funded by a grant from ZonMw (Dutch Organization for Health Research and Development), Program Common Diseases (4200.0012)

\section{Ethical approval}

The Dutch Central Committee on Research involving Human Subjects (CCMO) approved the study (P04.1341C)

\section{Competing interests}

The authors have stated that there are none

\section{Acknowledgements}

We wish to thank the parents of the children who participated in this study, the receptionists of the GP cooperative in Rotterdam South, and Eef van Dijk, director of the Central GP cooperatives Rijnmond.

\section{Discuss this article}

Contribute and read comments about this article on the

Discussion Forum: http://www.rcgp.org.uk/bjgp-discuss

\section{REFERENCES}

1. Bruijnzeels MA, Foets M, van der Wouden JC, et al. Everyday symptoms in childhood: occurrence and general practitioner consultation rates. Br J Gen Pract 1998; 48(426): 880-884.

2. Moll van Charante EP. Dutch general practitioners in a time of change. Studies on out-of-hours and GP hospital care [Thesis]. Amsterdam: Academic Medical Centre - University of Amsterdam, 2007.

3. Boomsma LJ, van der Meulen P, Uitewaal PJM, et al. NHG practice guideline. Children with fever. Huisarts Wet 1999; 42: 206-218.

4. Dutch College of General Practitioners. NHG-Telefoonwijzer voor triage en advies. [Dutch Collge of GPs' Telephone guideline for triage and advice]. Utrecht: NHG, 2002. http://nhg.artsennet.nl (accessed 3 Jan 2008).

5. Richardson M, Lakhanpaul M. Guideline Development Group and the Technical Team. Assessment and initial management of feverish illness in children younger than 5 years: summary of NICE guidance. BMJ 2007; 334(7604): 1163-1164.

6. Van den Bruel A, Bartholomeeusen S, Aertgeerts B, et al. Serious infections in children: an incidence study in family practice. $B M C$ Fam Pract 2006; 7: 23.

7. Okkes IM, Oskam SK, Lamberts H. Van klacht naar diagnose. Episodegegevens uit de huisartspraktijk [From complaint to diagnosis. Episodic data from general practice.]. Bussum: Coutinho, 1998. 